\title{
Produção Científica e Rede de Pesquisadores em Administração Pública no Brasil: uma investigação sobre a primeira década dos anos 2000
}

Corrêa, Victor; de Souza Coelho, Fernando; Trottmann, Paula; Mori Sarti, Flavia

Produção Científica e Rede de Pesquisadores em Administração Pública no Brasil: uma investigação sobre a primeira década dos anos 2000

Administração Pública e Gestão Social, vol. 11, núm. 3, 2019

Universidade Federal de Viçosa, Brasil

Disponível em: http://www.redalyc.org/articulo.oa?id=351559268003

Esta obra está bajo una Licencia Creative Commons Atribución-NoComercial-SinDerivar 3.0 Internacional. 


\section{Produção Científica e Rede de Pesquisadores em Administração Pública no Brasil: uma investigação sobre a primeira década dos anos 2000}

Scientific Production and Network of Researchers in Public Administration in Brazil: an investigation about the first decade of the 2000s.

Producción Científica y Red de Investigadores en Administración Pública en Brasil: una investigación sobre la primera década de los años 2000.

Victor Corrêa

Universidade de São Paulo, Brasil

Redalyc: http://www.redalyc.org/articulo.oa?

prof.victorcorrea@gmail.com

Fernando de Souza Coelho

Universidade de São Paulo, Brasil

fernandocoelho@usp.br

Paula Trottmann

Universidade Federal de São Carlos, Brasil

trottmannpaula@gmail.com

Flavia Mori Sarti

Universidade de São Paulo, Brasil

flamori@usp.br $\mathrm{id}=351559268003$

Recepção: 24 Março 2018

Aprovação: 16 Março 2019

Publicado: 01 Julho 2019

\section{Resumo:}

Este artigo descreve e analisa os resultados de uma pesquisa sobre a rede de produção científica em Administração Pública no Brasil no período de 2000 a 2010. Metodologicamente, foram coletados os dados dos principais eventos e periódicos nacionais que ampararam o campo do saber na última década. Como resultado, verificou-se o crescimento do volume da produção científica e do número de pesquisadores, o padrão de colaboração e a categorização do perfil dos autores, a identificação dos mais prolíficos, além da ilustração da rede de pesquisa e das medidas de propriedade. Esses índices permitiram tanto rediscutir alguns problemas históricos do campo, já levados a cabo por outros autores, como desvelar algumas características dessa comunidade acadêmica no presente, tais como: a persistência da falta de identidade e insuficiente delimitação do campo do saber, a hodierna dispersão, 'vale tudo' temático na produção científica e a existência de um rol de autores continuantes bastante reduzido.

Palavras-chave: Administração Pública, Produção Científica, Comunidade Acadêmica, Brasil.

\section{Abstract:}

This article describes and analyzes the results of a research on the network of scientific production in Public Administration in Brazil from 2000 to 2010. Data were collected from the main national events and periodicals that supported the field of knowledge in the 2000s. As a result, the amaount of scientific production and the number of researchers, the pattern of collaboration and the profile categorization of the authors, the identification of the most prolific, as well as the illustration of the research network and property measures were verified. These indexes allowed this paper to re-discuss some of the historical problems of the field, already carried out by other authors, and to reveal some characteristics of this academic community in the present, such as: the persistence of the lack of identity and insufficient delimitation of the field of knowledge, the lack of a thematic definition in the scientific production and the existence of a very reduced number of authors that address the theme.

Keywords: Public Administration, Scientific Production, Academic Community, Brazil.

\section{Resumen:}


Este artículo describe y analiza los resultados de una investigación sobre la red de producción científica en Administración Pública en Brasil en el período de 2000 a 2010. Metodológicamente, se recolectaran los datos de los principales eventos y periódicos nacionales que ampararon este campo del saber en la última década. Como resultado, se verificó el crecimiento del volumen de la producción científica y del número de investigadores, el stándar de colaboración y la categorización del perfil de los autores, la identificación de los más prolíficos, además de la ilustración de la red de investigación y de las medidas de propiedad. Estos índices permitieron tanto rediscutir algunos problemas históricos del campo, ya llevados a cabo por otros autores, como desvelar algunas características de esa comunidad académica en el presente, tales como: la persistencia de la falta de identidad e insuficiente delimitación del campo del saber, la actual dispersión, la falta de definición temática en la producción científica y la existencia de un reducido número de autores continuantes.

Palabras Clave: Administración Pública, Producción Científica, Comunidad Académica, Brasil.

\section{INTRODUÇÃo}

Este artigo é um dos subprodutos de um projeto de pesquisa, realizado no quinquênio 2012-2016, sobre a produção científica em Administração Pública no Brasil na primeira década de 2000, e apresenta os resultados inéditos dessa investigação. A ideia de desvelar as características de subáreas da Ciência Administrativa nacional remete, por exemplo, aos trabalhos realizados por Rossoni et al (2008), Hocayen-da-Silva et al (2008), Rossoni et al (2009) e Martins et al (2010) para os campos do saber de Administração da Informação, Administração Pública e Gestão Social, Administração de Ciência e Tecnologia (C\&T) e Gestão de Operações, respectivamente. Todos utilizam, pioneiramente, a análise de redes sociais justaposta à análise bibliométrica para caracterizar a produção científica e evidenciar a organização da comunidade acadêmica dessas áreas funcionais da Administração no país na última década.

O objetivo de levar a cabo e bom termo uma análise longitudinal da produção científica em Administração Pública (AP) no Brasil no período de 2000 a 2010, a partir da análise de redes, é levantar dados e informações que permitam aprofundar as discussões sobre as características desse campo do saber no país. Os estudos que se utilizam de métodos, ferramentas e técnicas de modelagem de sistemas complexos ${ }^{[\mathrm{i}]}$, em conjunto com a análise bibliométrica, oferecem um upgrade analítico em relação à bibliometria meramente descritiva, bem como amparam quantitativamente algumas intepretações de ensaios teóricos e/ou pesquisas teóricoempíricas qualitativas.

A pesquisa da qual deriva esse artigo justifica-se pela continuidade de investigações que analisam criticamente o campo do saber de AP a partir da sua rede de produção científica no país, atualizando o horizonte temporal. Machado-da-Silva et al (1990) foram os precursores de trabalhos sobre a produção científica brasileira em Administração (ADM) - no caso, de organizações. Esse trabalho inaugurou tal análise na comunidade acadêmica de ADM, demonstrando a importância de se refletir qualitativa e quantitativamente sobre a produção científica dessa área de conhecimento. Decorridos 20 anos, trabalhos como o de Rossoni, Guarido Filho e Machado-da-Silva (2010) recolocaram em pauta essa agenda de pesquisa com a abordagem de redes, instigando o uso de ferramentas e técnicas de redes sociais na análise de comunidades acadêmicas de ADM.

Especificamente sobre a subárea de Administração Pública no Brasil, destacam-se os estudos de: Souza (1998), que aponta algumas fragilidades da agenda de pesquisa de AP na década de 1990, como a não cumulatividade do conhecimento; Keinert (2000), que investiga, a partir da análise dos artigos publicados nos periódicos Revista de Administração Pública (RAP) e Revista do Serviço Público (RSP) no período de 1937 a 1997, a crise e mudança de paradigmas da AP brasileira no século XX - de estadocêntrica para sociocêntrica; Pacheco (2003), que discute algumas limitações da produção científica em Administração Pública no país entre meados de 1990 e o limiar dos anos 2000, como a dispersão da produção científica; Hocayen-da-Silva et al (2008), que apresentam um balanço sobre a produção científica em AP e Gestão Social, analisando os artigos publicados nos anais dos Encontros da Associação Nacional de Pós-Graduação e Pesquisa em Administração, realizados anualmente, entre 2000 e 2005, destacando o aumento do volume de 
artigos e da colaboração científica; Fadul et al (2010), que refletem sobre o campo do saber em AP, mostrando seus entraves (ausência ou insuficiência de delimitação, por exemplo) e ensaiando explicações para tais; Peci et al (2011), que avaliam a produção científica em Administração Pública no país a partir dos paradigmas de pesquisa; Fadul et al (2011), que realizam uma análise bibliométrica sobre a produção científica dos Encontros da Divisão Acadêmica de Administração Pública da ANPAD - o EnAPG - nos anos 2000; Fadul e Coelho et al (2014), que discorrem sobre a evolução do campo de saber em AP no Brasil, evidenciando o crescimento do número de cursos de graduação, de pós-graduação, de eventos e revistas nacionais, e da produção científica nos anos pós-2000; e Smolski et al (2017), que realizam uma análise bibliométrica da produção científica na RAP entre os anos de 2003 e 2016, principal periódico de AP do país.

A tabela 1 abaixo dispóe essas contribuições anteriores - título, autor/autores e ano -, indicando a abordagem metodológica de cada investigação, se qualitativa ou quantitativa. Cabe frisar que a abordagem indicada não representa, necessariamente, a metodologia integral de cada trabalho, mas aponta o viés da pesquisa. Em suma, os trabalhos elencados são fulcrais para a compreensão do campo do saber em AP no Brasil, e seus resultados, a priori, são pressupostos deste artigo. 
Tabela 1 - Principais Trabalhos sobre o Campo do

Saber em Administração Pública nos últimos 30 anos

\begin{tabular}{|c|c|c|c|}
\hline Título & Autores & Ano & Abordagem \\
\hline $\begin{array}{l}\text { Pesquisa em } \\
\text { Administração } \\
\text { Pública no Brasil: } \\
\text { uma agenda para } \\
\text { debate. }\end{array}$ & Souza, C. & 1998 & Qualitativa \\
\hline $\begin{array}{l}\text { A administração } \\
\text { pública no Brasil: } \\
\text { crises e mudanças de } \\
\text { paradigmas. }\end{array}$ & $\begin{array}{l}\text { Keinert, T. M. } \\
\text { M. }\end{array}$ & 2000 & Qualitativa \\
\hline $\begin{array}{l}\text { Administração } \\
\text { Pública nas Revistas } \\
\text { Especializadas - } \\
\text { Brasil, } 1995-2002 .\end{array}$ & Pacheco, R. S. & 2003 & Qualitativa \\
\hline $\begin{array}{l}\text { Administração } \\
\text { pública e gestấo } \\
\text { social: a produção } \\
\text { científica brasileira } \\
\text { entre } 2000 \text { e } 2005 \text {. }\end{array}$ & $\begin{array}{l}\text { Hocayen-da- } \\
\text { Silva, A.J.; } \\
\text { Rossoni, L; } \\
\text { Ferreira } \\
\text { Junior, I. }\end{array}$ & 2008 & Quantitativa \\
\hline $\begin{array}{l}\text { Ensaiando } \\
\text { Explicações e } \\
\text { Explorando } \\
\text { Caminhos para o } \\
\text { Campo da } \\
\text { Administração } \\
\text { Pública. }\end{array}$ & $\begin{array}{l}\text { Fadul, E.; } \\
\text { Silva, M. M.A.; } \\
\text { Silva, L. P. }\end{array}$ & 2010 & Qualitativa \\
\hline $\begin{array}{l}\text { Paradigmas } \\
\text { Orientadores da } \\
\text { Pesquisa em } \\
\text { Administração } \\
\text { Pública no Contexto } \\
\text { Brasileiro. } \\
\end{array}$ & $\begin{array}{l}\text { Peci, A.; } \\
\text { Ribeiro, A.J. } \\
\text { G.; Rodrigues, } \\
\text { F.B.S.; } \\
\text { Forzanin, M. }\end{array}$ & 2011 & Qualitativa \\
\hline $\begin{array}{l}\text { Uma Análise do } \\
\text { Campo da } \\
\text { Administração } \\
\text { Pública através da } \\
\text { Produção Científica } \\
\text { Publicada nos Anais } \\
\text { dos EnAPGs. }\end{array}$ & $\begin{array}{l}\text { Fadul, E.; } \\
\text { Silva, L. P.; } \\
\text { Cerqueira, L. } \\
\text { S. }\end{array}$ & 2011 & Qualitativa \\
\hline $\begin{array}{l}\text { Administração } \\
\text { pública no Brasil: } \\
\text { reflexões sobre o } \\
\text { campo de saber a } \\
\text { partir da Divisão } \\
\text { Acadêmica da } \\
\text { Associação Nacional } \\
\text { de Pós-Graduação e } \\
\text { Pesquisa em } \\
\text { Administração (2009- } \\
\text { 2013). }\end{array}$ & $\begin{array}{l}\text { Fadul, E.; } \\
\text { Coelho, F.S.; } \\
\text { Costa, F.J.L.; } \\
\text { Gomes, R.C. }\end{array}$ & 2014 & Qualitativa \\
\hline $\begin{array}{l}\text { Análise do perfil da } \\
\text { produção científica } \\
\text { da Revista de } \\
\text { Administração } \\
\text { Pública (RAP) no } \\
\text { período } 2003-2016 \text {. }\end{array}$ & $\begin{array}{l}\text { Smolscki, F. } \\
\text { M.; Dalcin, D.; } \\
\text { Visentini, M.; } \\
\text { Bamberg, J.; } \\
\text { kern, J. S. }\end{array}$ & 2017 & Quantitativa \\
\hline
\end{tabular}

Fonte: elaborado pelos autores.

Pela tabela 1, observa-se que a abordagem qualitativa é predominante na investigação sobre a comunidade acadêmica e a produção científica em AP no país nos últimos 30 anos. São análises baseadas em percepções 
de pesquisadores que, muitas vezes, lideraram a área de AP nos Encontros Nacionais da Associação de PósGraduação e Pesquisa em Administração (EnANPADs) e EnAPGs, como Fadul, Peci, Pacheco e Souza, nesse período, ou que realizaram tese em tal tema, utilizando-se da análise de conteúdo, como Keinert (2000). Por sua vez, os trabalhos quantitativos não interpretaram de maneira plena a relação entre os dados e informações obtidos com a institucionalidade (trajetória, organização e atributos) do campo brasileiro do saber em AP. Considerando essa lacuna, este artigo realiza, adicionalmente, uma triangulação quali-quanti para descrever e analisar alguns resultados de uma investigação sobre a produção científica em AP no Brasil na primeira década dos anos 2000. A complementariedade das abordagens ocorre na intersecção entre as métricas advindas da análise bibliométrica e de redes, aproximando-se da contribuição quantitativa de Hocayen-da-Silva et al (2008) e ampliando o período para toda a década, com as apreciações qualitativas (e opiniões de observadoresparticipantes da comunidade acadêmica de AP nacional) de Souza (1998), Pacheco (2003) e Fadul et al (2010).

\subsection{Justificativa do trabalho, premissas da investigação e o objetivo deste artigo}

É com o pano de fundo descrito na introdução e considerando a problemática recorrente do campo do saber em AP no Brasil desde os anos 1990 que os autores deste trabalho elaboraram um projeto de pesquisa no quadriênio 2012-2016, baseado na modelagem de redes complexas, para mapear a produção científica e jogar luz na configuração da comunidade acadêmica de AP na primeira década dos anos 2000, um período profícuo de (re)fortalecimento da Administração Pública como subárea (ou subdisciplina) da Administração no Brasil, conforme atestam Fadul e Coelho et al (2014). A ampliação do papel do Estado, a diversificação das políticas públicas e os arranjos com o terceiro setor (Estado-Rede) desdobraram a agenda governamental e, por conseguinte, o rol de pesquisas e a audiência dessas investigações em nível nacional.

Uma radiografia da última década, marcada pela explosão de cursos de graduação em AP (assim como de Gestão Pública, Gestão de Políticas Públicas e Gestão Social), pelo surgimento de alguns programas de pósgraduação nesse campo do saber e pela ampliação dos eventos acadêmicos (EnAPGs, por exemplo), permite não apenas descrever a evolução da produção científica em AP no país, mas também refletir sobre o seu desenvolvimento nesse período.

O estudo intenta oferecer dados e informações que dialoguem especificamente com algumas das premissas intuitivas dos trabalhos anteriores, citados na tabela 1 , que identificaram elementos estruturantes do campo do saber em AP no Brasil. Em linhas gerais, interpenetrando as leituras de Souza (1998), Pacheco (2003) e Fadul et al (2010), pode-se classificar a produção científica em Administração Pública no país como:

$\S$ Dispersa e pouco delimitada, versando sobre muitos assuntos não relacionados ao cerne da própria Administração Pública;

$\S$ Saturada e exaustiva quando se arraiga a determinadas temáticas, enquanto existem outras ainda inexploradas;

$\$$ Seguidora de modismos, realizando pesquisas conforme as ondas da pauta governamental e

$\S$ Carente de questões de pesquisa claras e próprias do campo do saber, isto é, sem autonomia.

Partindo desse diagnóstico preliminar, é possível conjecturar que uma investigação sobre a produção científica em AP na última década, abarcando os principais eventos e periódicos nacionais, possa fornecer subsídios para (re)analisar essas características da comunidade acadêmica e da rede de pesquisadores existente no Brasil.

Assim, no âmbito do projeto de pesquisa realizado, o papel deste artigo é o de apresentar alguns resultados sobre a rede de produção científica em AP no Brasil no período de 2000 a 2010, quais sejam:

- A evolução do volume de artigos; 
- A evolução do número de pesquisadores;

- A apresentação dos índices de autoria, colaboração e produtividade;

- A categorização do perfil dos autores;

. O apontamento da relação dos pesquisadores "continuantes" e da lista dos mais prolíficos e

- A ilustração da rede de pesquisadores e o cálculo das medidas de propriedade estrutural, a saber: centralidade de grau, centralidade de intermediação e autovetor.

Para tanto, a seguir é exposta a revisão da literatura (seção 2) e elucidada a metodologia de pesquisa (seção 3). Na seção 4 são descritos e analisados os resultados e, encerrando o artigo, a seção 5 apresenta as considerações finais.

\section{Revisão da Literatura: fundamentos sobre o Campo do SAber Em AP no Brasil[it]}

Resgatando as características intrínsecas à formação da área de conhecimento em AP no Brasil, Keinert (1994) analisa os paradigmas da Administração Pública no século XX, desde a República Velha ao processo de redemocratização na década de 1980. Nessa análise, a autora demonstra que múltiplas influências intelectuais, de distintas disciplinas, ocorreram, caracterizando a AP como um campo do saber multidisciplinar (em vez de uma área de conhecimento ou disciplina, na acepção tradicional). Cabe ressaltar que essa trajetória não é exclusivamente brasileira, mas uma realidade da conformação da $\mathrm{AP}$ em diversas nações, considerando que:

(...) de la ciencia politica hereda la importancia del poder, la política e las políticas publicas; de la administración, elementos sobre las funciones administrativas, la toma de decisiones y los sistemas de información; de la sociología, hereda elementos del enfoque de sistemas, la importancia de la teoria organizacional y la teoria de la burocracia; la historia, la economia y la psicologia, introducen el análisis histórico sobre decisiones administrativas; herramientas económicas sobre finanzas públicas, presupuesto y política fiscal; y luces sobre el comportamento de los actores y grupos que forman las organizaciones públicas (Stillmann, 1991 apud Ospina Bozzi, 1998, p.4).

A face multidisciplinar da AP cria empecilhos para a autonomia do campo científico, haja vista a indefinição de quais são suas teorias e doutrinas específicas dentro de seu espaço de ação. Ou seja, esse microcosmo, para utilizar os termos de Bourdieu (2004), ainda não tem a delimitação de sua própria concepção. Fato é que, se a Administração Públicaesteve ligada à administração de empresas e às ciências jurídicas na primeira metade do século XX, não permitindo a sua caracterização explícita como tal, no pósguerras congregou novas ascendências advindas da Ciência Política, da Sociologia e da Economia, dando continuidade ao conceito de que a Administração Pública é subalterna a diversas disciplinas, dificultando a sua demarcação (e independência) científica (Pacheco, 2003; Fadul \& Silva, 2009).

Análise análoga pode se obtida a partir do trecho de Fadul et al. (2010), segundo o qual "a área tem sido tratada como um conjunto inespecífico de temas que perpassam o campo do Direito, da Ciência Política, da Sociologia, da Economia e que, algumas vezes, podem ser colocadas dentro do campo da Administração". Este posicionamento revela per si a falta de identidade do campo do saber em AP. Souza (1998), ainda nos anos 1990, destacava as dificuldades da AP como sendo as suas limitações de conceitos e metodologias. Tais dificuldades, resultado da imbricação de várias disciplinas que conformam a Administração Pública como campo do saber, provocam, segundo a autora, ausência de uniformidade conceitual e insuficiência da tradição de linhas de pesquisa. E completa:

O campo [do saber de AP] é suficientemente eclético para comportar teorias e conceitos vindos de outras áreas das ciências sociais. Mas o que é importante é que os pesquisadores têm de ser explícitos sobre a bagagem intelectual que eles estão usando para a análise do problema a ser pesquisado. (Souza, 1998, p.54). 
Ocorre que, a partir da análise das publicações do EnAPG, Fadul et al (2011) constatam que as pesquisas sobre AP no Brasil consideram, sobremaneira, a Administração Pública como o locus de pesquisa e não como focus teórico. Logo, o campo do saber torna-se acolhedor de qualquer assunto ou tema que verse sobre a área pública (uma organização pública, uma política pública, etc), ainda que a questão de pesquisa não seja, epistemologicamente, de Administração Pública. Tal fato é revelado a partir da evidenciação da "variedade de assuntos abordados". (Fadul et al. ,2011, p.13).

Machado-da-Silva et al (1990) ainda destacam que as metodologias de pesquisa empregadas são, muitas vezes, inadequadas à investigação em Administração Pública. Segundo os autores, as pesquisas caracterizamse por serem demasiadamente normativas, reforçando a insuficiência de método científico em suas elaborações. Tal interpretação é referendada por Pacheco (2003), que detecta a falta de rigor metodológico como um dos problemas do campo do saber em AP no Brasil. Ademais, a pesquisadora aponta que a comunidade acadêmica de Administração Pública é diminuta, o que dificulta a sua autonomia.

Fadul et al (2010) ponderam que a produção científica em Administração Pública, apesar de não chegar ao ponto de se tornar subordinada, influenciada por qualquer demanda, conforme conceitua Bourdieu (2004), como "ciência escrava", é influenciada fortemente pelo contexto sociopolítico, ou seja, responde às demandas do Estado e da sociedade. A preponderância desse contexto pode ser observada, no decorrer dos tempos, a partir dos rumos do ensino e da pesquisa em Administração Pública, conforme as mudanças de paradigmas no Estado brasileiro. O período pós-reforma do aparelho do Estado de 1995, a chamada Reforma Gerencial, ilustra tal fato, com relações entre a agenda governamental e a agenda de pesquisa, como demonstram Pacheco (2003) e Fadul et al (2011).

Ocorre que os pesquisadores, ao privilegiarem os temas da atualidade nas suas pesquisas, provocam a falta de continuidade, pois seguem frequentemente as tendências da época (ou os temas da moda). Em adição, observa-se que a Administração Pública, como locus profissional, não se caracteriza como um campo do saber estritamente científico, fortalecendo o interesse por temáticas em voga na pauta público-estatal. Nesse sentido, a AP "se apresenta aos estudiosos como teoria, como ideologia, como técnica e como prática." (Fadul, et al., 2012, ).

Para além das interrelações da pesquisa com a agenda governamental, ao analisar a produção científica em AP em revistas e eventos, Pacheco (2003) verificou a dispersão temática como um problema, com os artigos tratando de temas variados, sem conexão entre si, sem profundidade e sem cumulatividade das temáticas, no "calor do momento". O grande problema em abordar os modismos é que os autores-atores (professores e gestores públicos, simultaneamente), às vezes, não têm o distanciamento necessário para análises mais criteriosas e independentes.

Fadul et al (2010), por sua vez, classificam a produção científica em Administração Pública como "um conjunto inespecífico de temas". Para tanto, destacam que as submissóes de artigos sobre o assunto cresceram nos anos 2000, quando analisados os anais dos Encontros da Associação Nacional de Pós-Graduação e Pesquisa em Administração (EnANPADs). Entretanto, os autores afirmam que o crescimento da produção se deve, sobretudo, ao interesse momentâneo de pesquisadores de diversas divisões acadêmicas da ANPAD em estudarem organizações públicas a partir de referenciais teóricos de áreas funcionais da Administração (de Empresas). Isto é, a AP tornou-se um objeto de estudo chamariz na última década pelo incremento do papel do Estado no Brasil.

Vale dizer que o crescimento da produção científica em AP levou à criação, em 2004, de um evento da área, o EnAPG. Todavia, apesar desse alento, o trabalho que analisa as quatro primeiras edições do evento, realizado por Fadul et al (2011), permite constatar, ainda, a fragilidade e indefinição da Administração Pública como focus. A letra G do EnAPG, que significa Governança, atraiu, por exemplo, uma variedade de artigos sobre Governança Corporativa nos eventos, enquanto a Governança Pública não é explorada.

Um dos caminhos para se estabelecer uma produção científica realmente condizente com a natureza do campo do saber, e não uma simples abordagem pelo locus (objeto empírico), é tratado por Behn (1995), que 
defende que a AP deve ser norteada por big questions que impulsionem as pesquisas, tal como um ponto de partida. A falta de questões - e de problemas claramente identificados e compartilhados na comunidade acadêmica de AP - resulta em fragmentação temática. Consequentemente, sem questões comuns, sem aprofundamento e continuidade de estudos, a acumulação do conhecimento é prejudicada, com a escassez de pesquisas perenes e consolidadas sobre determinadas questões. Ademais, alguns autores, como Fadul et al (2011), afirmam que muitos pesquisadores (comumente os mais ligados ao mundo prático) não se preocupam em verificar o que já foi produzido sobre suas temáticas em termos de uma revisão sistemática da literatura, ignorando os avanços já realizados sobre o assunto a ser abordado. Portanto, o resultado acaba sendo a profusão de artigos com referencial bibliográfico defasado e com análises simples e superficiais.

Sucessivo ao problema de identificação e delimitação, provocando variadas e diferentes abordagens, com temas que muitas vezes não deveriam estar relacionados ao campo do saber, volta-se à velha problemática já abordada, relacionada à lente teórica e ao aporte metodológico adotado pelos pesquisadores. É nesse sentido que Pacheco (2003) define a Administração Pública no Brasil como "uma área dispersa, sem acumulação de conhecimento (...) e com análises a priori sem comprovações”. A multiplicidade de maneiras de se analisar os problemas, combinados com a diversidade de temáticas e a falta de rigor metodológico, produzem muitos estudos que não contribuem efetivamente para construção de conhecimento no campo da AP.

Percebe-se, então, um campo do saber frágil devido a sua indefinição, sem limites estabelecidos que direcionem a produção científica para questões próprias (Fadul et al, 2010). Necessita-se, portanto, de uma delimitação, direcionando os estudos para que contemplem os interesses centrais da Administração Pública como campo científico, evitando a produção acadêmica sem foco (Pacheco, 2003). Tentativas de delimitação na última década podem ser observadas a partir da estruturação de uma divisão acadêmica exclusiva de Administração Pública (APB) na ANPAD, a partir de 2009. Fadul \& Coelho et al (2014) descrevem o processo de reconstrução dos temas de AP nessa Associação no quadriênio 2009-2013.

Por fim, pode-se conjecturar que a falta de apoio institucional próprio para a subárea de Administração Pública no Brasil também pode ser apontada como um senão para o desenvolvimento institucional do campo do saber na primeira década dos anos $2000^{[i i i]}$. Nesse caso, destaca-se a escassez de revistas próprias de AP, de programas estritamente ligados à AP no sistema de pós-graduação nacional e a não diferenciação simbólica entre Administração Pública (na tradição de Public Administration) e Administração de Empresas (na acepção de Management). Outrossim, a pressão do Sistema CAPES por publicação a partir do final dos anos 2000, principalmente em termos quantitativos, acabou por retroalimentar as problemáticas relacionadas à "escolha de abordagens que apresentem menores exigências científicas e metodológicas". É um processo de simplificação e comodismo, segundo Fadul et al (2011).

A partir dos autores consultados e da bibliografia revisada, pode-se compreender o campo do saber em AP no Brasil, na última década, como frágil e fragmentado, destacando os principais problemas, que se sobrepõem e se complementam:

- Falta de identidade própria, devido à origem e evolução do campo do saber, fundamentado em outras disciplinas;

- A falta de identidade é reforçada pela falta de delimitação, já que não existem limites sobre o que é o campo do saber em AP e tampouco uma definição de quais são questões de pesquisa;

- Nesse aspecto encontram-se também os problemas relacionados à falta de rigor metodológico nas pesquisas realizadas, acentuada pela normatividade do campo do saber e pela característica de autores-gestores sem tradição em projetos de pesquisas perenes e de fôlego;

- Consequentemente, observa-se a ocorrência do vale-tudo temático, com abordagens irrestritas sobre temas - muitas vezes não relacionados à Administração Pública - e, com isso, a perpetuação da não cumulatividade e fragmentação das pesquisas; 
- A falta desses elementos provoca o modismo por parte dos pesquisadores que, sem um norteamento sobre o campo e seu objeto de estudo, desenvolvem pesquisas seguindo a agenda governamental, o que não ajuda na verticalização das investigações e na formação de especialistas temáticos.

- A comunidade científica de Administração Pública no país ainda é restrita e pequena, pecando pela autorreferência nos artigos e pela baixa internacionalização;

- A falta de apoio institucional próprio cria barreiras para o desenvolvimento do campo do saber, considerando que o incentivo para o ensino e a pesquisa em Administração Pública ainda carecem de especificidade no âmbito da comunidade acadêmica de Administração e do Sistema de C\&T no Brasil.

Portanto, considerando os estudos realizados até então, por conta de todos os problemas destacados acima, o campo do saber em AP permanece frágil e fragmentado no Brasil, apesar de um crescimento observável de sua produção científica na última década. A figura 1 ilustra, tentativamente, essa problemática como um círculo vicioso.

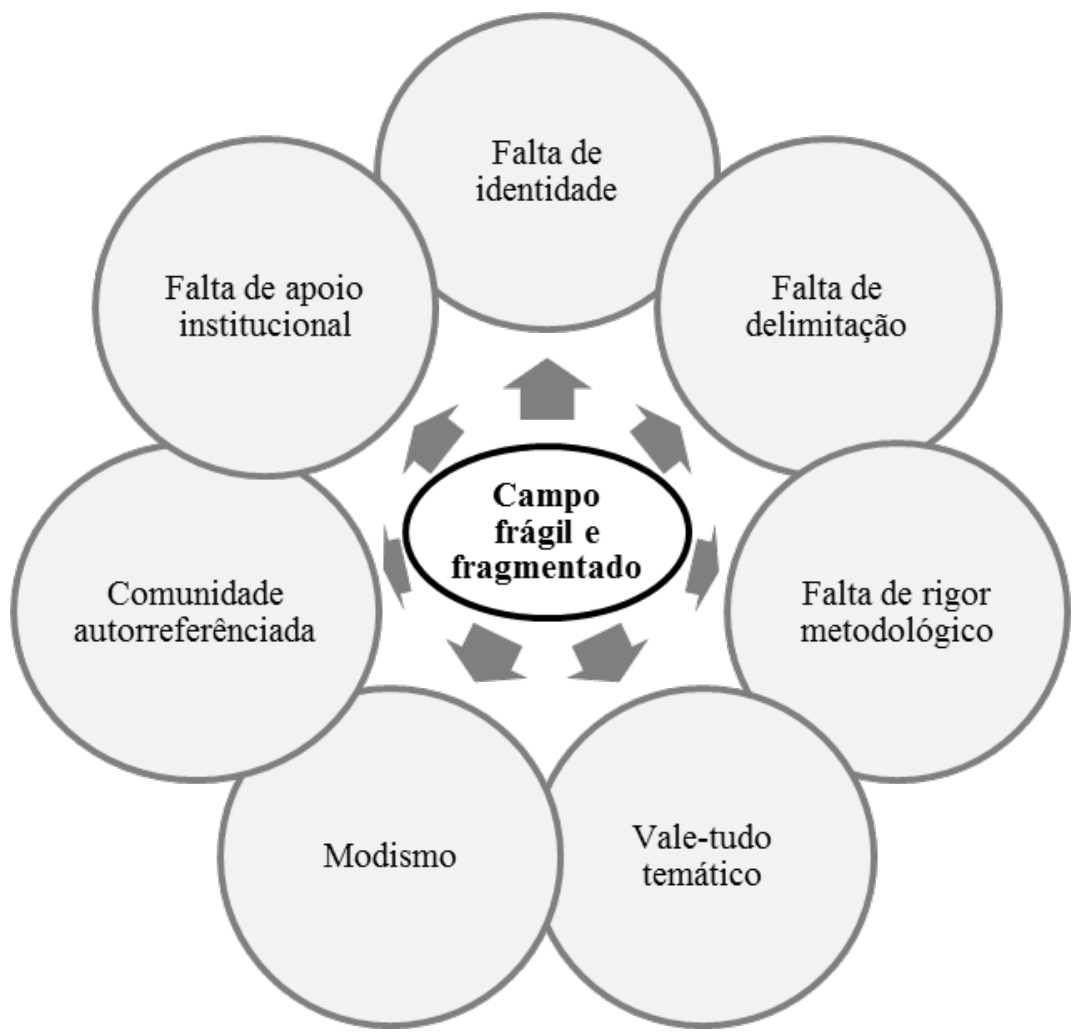

Figura 1 Problemáticas do Campo do Saber em Administração Pública no Brasil nos anos 2000 Fonte: elaborada pelos autores com base nos achados de Souza (1998); Pacheco, (2003); Hocayenda-Silva et al (2008); Fadul \& Silva (2010); Fadul et al (2011); Fadul \& Coelho et al (2014).

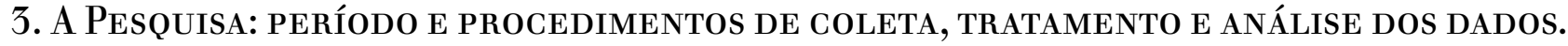

O mapeamento da rede de produção científica em AP no Brasil, a partir do ano de 2000 até o ano de 2010, compreende a década analisada pelos autores - mencionados na seção 2 -, que evidencia um aumento do volume de artigos e do número de pesquisadores, mas que aparentemente não contribui para atenuar os problemas da AP como campo do saber.

Considerando a impossibilidade de selecionar toda a produção científica nacional relacionada ao campo do saber em AP no período, optou-se por uma triagem dos principais eventos e periódicos, considerandoos como uma amostra representativa do universo das pesquisas dessa comunidade acadêmica no país. Logo, 
foram selecionados: (i) o Encontro Nacional da Associação de Pós-Graduação e Pesquisa em Administração (EnANPAD), no que se refere à divisão acadêmica de APB; (ii) o Encontro da Divisão de Administração Pública da ANPAD (EnAPG); (iii) a Revista de Administração Contemporânea (RAC); (iv) a Revista de Administração Pública (RAP); (v) a Revista do Serviço Público (RSP); e (vi) a Revista Organizações \& Sociedade (O\&S), que, em suma, são os principais eventos e os periódicos tipicamente de AP e/ou de ADM considerados como referência na última década.

Nos casos em que houve a necessidade de pré-seleção dos artigos devido à abrangência da linha editorial do periódico (RAP [iv], RAC e O\&S), foi realizada a seleção de artigos adotando o critério de enquadramento de acordo com os temas de interesse apresentado pelo EnAPG na edição 2012, considerando que esse evento, por ser um congresso do campo do saber de AP, congrega as diretrizes/orientações que permitem tal classificação. Apesar de os artigos selecionados compreenderem o período até 2010, a edição do EnAPG de 2012 foi considerada devido ao fato de que os oito temas[v] são resultados da análise da produção científica de AP na última década, conforme afirmam Fadul \& Coelho et al (2014). Nesses casos, o enquadramento dos artigos foi realizado com base no título e no resumo.

A coleta dos dados foi realizada a partir do website dos eventos e periódicos, que disponibilizam suas edições em formato eletrônico para acesso irrestrito (como nos casos dos periódicos, nos quais era possível ter acesso ao trabalho completo), ou acesso restrito (como os eventos, que possibilitam o acesso completo apenas a associados, permitindo aos visitantes apenas a visualização dos títulos, resumos e autores dos trabalhos publicados).

Para sistematização dos dados coletados foi utilizado o programa Microsoft Office Excel 2010 e, posteriormente, o Programa Node XL, que possibilitou a criação de gráficos e imagens de redes sociais a partir das planilhas eletrônicas, permitindo a obtenção de índices bibliométricos e a análise da rede de pesquisadores. Inicialmente, realizou-se os cálculos sobre o volume da produção científica do campo do saber em AP, tanto em termos da quantidade de artigos quanto em relação ao número de pesquisadores. $\mathrm{Na}$ sequência, procedeu-se à análise do grau de colaboração e produtividade da rede de pesquisadores, utilizando, para tanto, a análise dos graus de artigo, autores, autoria, colaboração e produtividade. Tal processo foi realizado, anteriormente, no trabalho de Martins (2009), com base em Hocayen-da-Silva et al. (2008), seguindo os elementos apresentados no quadro 1.

Quadro 1 Elementos analisados nos eventos e periódicos e seus respectivos significados

\begin{tabular}{l|l}
\hline Elementos & Significado \\
\hline Artigos & Número de cada um dos artigos publicados \\
\hline Autores & $\begin{array}{l}\text { Número de pesquisadores em cada } \\
\text { evento/periódico }\end{array}$ \\
\hline Autorias & $\begin{array}{l}\text { Soma do número total de autores em cada } \\
\text { artigo }\end{array}$ \\
\hline Colaboração & Divisão de autorias pelos artigos \\
\hline Produtividade & $\begin{array}{l}\text { Divisão do número total de artigos pelo } \\
\text { número total de autores }\end{array}$ \\
\hline
\end{tabular}

Fonte: Elaborado pelos autores, com base em Hocayen-da-Silva et al (2008) e Martins (2009).

Em adição, com base no trabalho de Rossoni et al (2010), foi realizada a análise de categorização do perfil dos autores que compóem a rede de pesquisadores de AP no Brasil, definindo qual o enquadramento de cada um deles a partir dos critérios descritos no quadro 2. 
Quadro 2 Categorização do perfil dos autores com base na produção científica

\begin{tabular}{l|l}
\hline Categoria & Definição Operacional \\
\hline Continuantes & $\begin{array}{l}\text { Autores com mais de uma publicação em 5 ou } \\
\text { mais anos diferentes e ao menos uma nos } \\
\text { últimos 3. }\end{array}$ \\
\hline Transientes & $\begin{array}{l}\text { Autores com mais de uma publicação ao longo } \\
\text { do periodo analisado em não mais do que 4 } \\
\text { anos diferentes, sendo ao menos uma nos } \\
\text { úlimos 3 anos e ao menos uma em anos } \\
\text { anteriores. }\end{array}$ \\
\hline Ene-timers & $\begin{array}{l}\text { Auotres com apenas uma única publicação em } \\
\text { todo o periodo analisado. }\end{array}$ \\
\hline Retirantes & $\begin{array}{l}\text { Autores com mais de uma publicaçấo em um ou } \\
\text { mais anos diferentes nos últimos três anos } \\
\text { (exclusivamente). }\end{array}$ \\
\hline & $\begin{array}{l}\text { Autores com mais de uma publicação em um ou } \\
\text { mais anos diferentes, mas sem publicações nos } \\
\text { últimos 3 anos. }\end{array}$ \\
\hline
\end{tabular}

Fonte: Elaborado pelos autores, com base Rossoni et al (2010).

$\mathrm{Na}$ sequência, identificaram-se os pesquisadores continuantes e os mais prolíficos no campo do saber em AP, interpretando os resultados a partir de informações da plataforma Lattes do CNPq. Ao fim, obteve-se a ilustração da rede de pesquisadores e calculou-se as medidas de propriedade estrutural, nomeando os autores que se destacaram na centralidade de grau, centralidade de intermediação e na medida de autovetor.

\section{Descrição e AnÁlise dos Resultados}

O levantamento da produção científica em Administração Pública nos eventos e periódicos, no período de 2000 a 2010, somou um total de 2.218 artigos na última década, sendo 1.685 publicados em anais dos encontros e 533 nas revistas que compõem a amostra da pesquisa.

Assim, nota-se a evolução do número de publicações ao longo da década (gráfico 1), fato constatado anteriormente por Hocayen-da-Silva et al (2008), Fadul et al (2011) e Fadul \& Coelho et al (2014). No entanto, ressalva-se que o volume da produção científica alcança picos em anos pares, a partir de 2004, ano de início do evento EnAPG, concebido especificamente para apresentação dos artigos da comunidade acadêmica de Administração Pública. Interpretando esse resultado, pode-se afirmar que a elevação de artigos no decorrer dos anos não se refere ao número de programas de pós-graduação em $\mathrm{AP}$ - que aumentou, mas não de maneira significativa -, mas ao número de autores (professores-pesquisadores e alunos de pós-graduação) oriundos de cursos de mestrado e doutorado em Administração de Empresas e Contabilidade. Tal atração supostamente ocorreu tanto pela emergência do modelo da Administração Pública Gerencial que (re)aproximou a Gestão Pública da Gestão Empresarial no pós 1995, como pela percepção de que o campo do saber em AP, em seus eventos e nos seus periódicos, é plural e heterogêneo e, portanto, abarca de "tudo um pouco". 


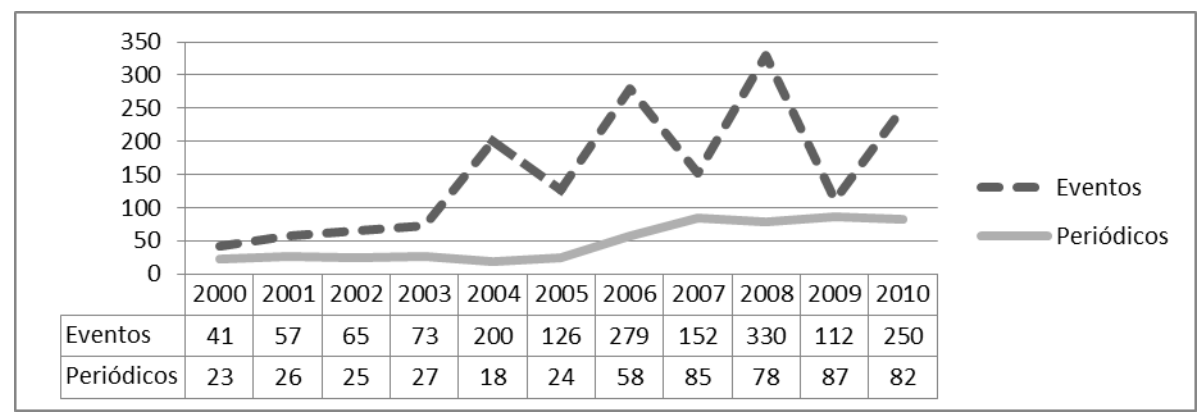

Gráfico 1 Produção Científica em AP no Brasil (2000-2010): evolução do volume de artigos Fonte: Elaborado pelos autores, a partir dos dados da pesquisa.

Complementarmente, é possível verificar (gráfico 2) a evolução no número de autores no período 2000-2010: de 81 pesquisadores no ano de 2000 para 747 pesquisadores no ano de 2010. Tal fato demonstra, naturalmente, a simetria entre o aumento do número de artigos e a elevação do número de autores a cada ano. Todavia, a relação direta e proporcional entre o crescimento do volume da produção científica e do número de pesquisadores no campo do saber não revela algo novo, visto que Hocayen-da-Silva et al (2008) e Fadul et al (2011) constataram resultado idêntico, apesar de analisarem horizontes temporais diferentes. Logo, é bem-vindo aprofundar tal análise e calcular, para além do volume da produção científica e do número de pesquisadores, o grau de colaboração e produtividade do campo do saber em AP.

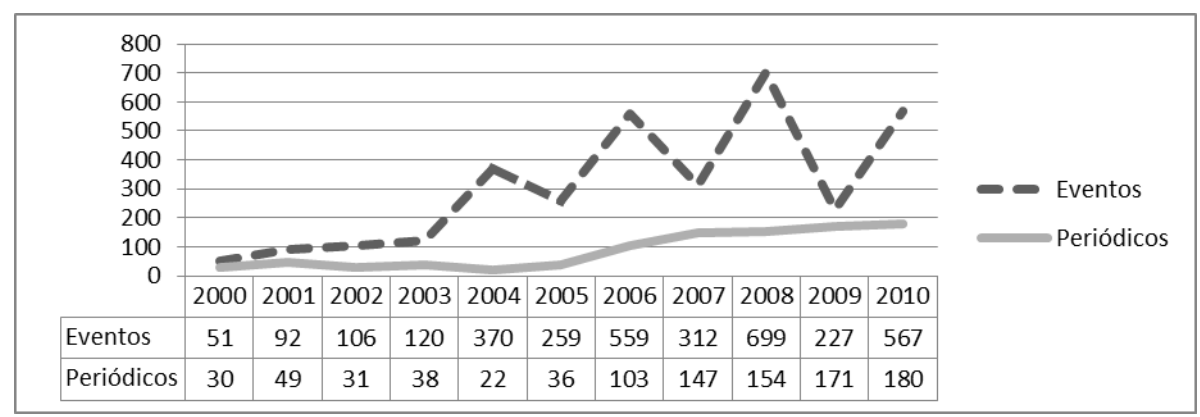

Gráfico 2 Produção Científica em AP no Brasil (2000-2010): evolução do número de pesquisadores Fonte: Elaborado pelos autores, a partir dos dados da pesquisa.

Para o cálculo dos índices bibliométricos de colaboração e produtividade, considerou-se: (a) artigos, o número de artigos publicados; (b) autores, o número de pesquisadores em cada evento/periódico (ressaltando-se, entretanto, que os pesquisadores podem se repetir, uma vez que podem publicar em eventos/ periódicos distintos); (c) autorias, soma do número total de autores em cada artigo; (d) colaboração, divisão de autorias pelos artigos e (e) produtividade, divisão entre o total de artigos pelo total de autores, conforme elucidado na seção 3 (quadro 1), e cujos resultados encontram-se na tabela 2, a seguir.

Tabela 2 Produção científica em AP no Brasil (2000-2010): índices de colaboração e produtividade

\begin{tabular}{l|l|l|l|l|l}
\hline Evento/Periódico & Artigos & Autores & Autorias & Colaboração & Produtividade \\
\hline EnANPAD & 1111 & 1590 & 2376 & 2,14 & 0,70 \\
\hline EnAPG & 574 & 1018 & 1348 & 2,35 & 0,56 \\
\hline O\&S & 41 & 66 & 76 & 1,85 & 0,62 \\
\hline RAC & 29 & 55 & 56 & 1,93 & 0,53 \\
\hline RAP & 266 & 465 & 573 & 2,15 & 0,57 \\
\hline RSP & 197 & 287 & 313 & 1,59 & 0,69 \\
\hline Total & 2218 & 3481 & 4742 & 2,14 & 0,64 \\
\hline
\end{tabular}


Fonte: Elaborado pelos autores a partir dos dados da pesquisa.

Os dados da tabela 2 mostram uma produção científica homogênea no campo do saber em AP no Brasil na última década, considerando que a colaboração e a produtividade não apresentam diferenças significativas entre os eventos e periódicos analisados. É uma subárea propensa a colaboração, com índice de 2,14. Essa média de dois autores por publicação alcança seu ápice $(2,35)$ no EnAPG, sendo possível conjecturar que as publicações em eventos tendem a ser mais colaborativas pelas relações de coautoria entre orientandos e orientador. Pressupõe-se que a RAP figure entre os dois eventos (EnAPG e EnANPAD) por ser uma publicação que recebe, seja pelo processo de fast track, seja por ser o periódico de referência da comunidade acadêmica de AP do país, os melhores trabalhos dos eventos. Por outro lado, destaca-se a RSP como o periódico com menor índice de colaboração (1,59), o que pode ser interpretado pelo posicionamento histórico dessa revista como um veículo voltado, principalmente, para os artigos escritos por practitioners da Gestão Pública que não guardam a tradição de coautoria acadêmica.

No que tange à produtividade, os índices entre eventos e revistas, igualmente, se assemelham e, nesse caso, o EnANPAD aparece como o de maior produtividade $(0,70)$, algo natural, por ser um evento tradicional da área de conhecimento de ADM que estimula a presença dos pesquisadores e a frequência como autores de artigo. Porém, a RSP, que figura entre os periódicos estudados como o de menor colaboração, apresenta a segunda maior produtividade, o que prova que esses índices bibliométricos devem ser analisados em pormenores para evitar interpretações equivocadas. Por conseguinte, é salutar apresentar alguns dados suplementares para o ajuste da análise sobre a rede de pesquisadores de AP.

O gráfico 3 e a tabela 3, abaixo, permitem considerações adicionais sobre o índice de grau de colaboração da rede de pesquisadores. Quando realizada a análise a partir de eventos e periódicos isoladamente, é possível conjecturar sobre cada um. Observa-se uma frequência modal de artigos (838) produzidos por dois autores, seguida por publicações individuais (725). Assim se caracteriza o campo do saber em AP no Brasil na última década, com produções científicas pareadas ou individuais, preferencialmente, decaindo vertiginosamente as produções com três e quatro autores, e assim sucessivamente. Destarte, apesar de os índices bibliométricos indicarem uma produção colaborativa, a análise desagredada dos dados mostra que, para além da prevalência de artigos com dois autores, é alto o número de produções científicas individuais. E, novamente, verifica-se que os eventos são veículos de publicação que incentivam presumivelmente a coautoria para além de dois autores, quando comparado com os periódicos.

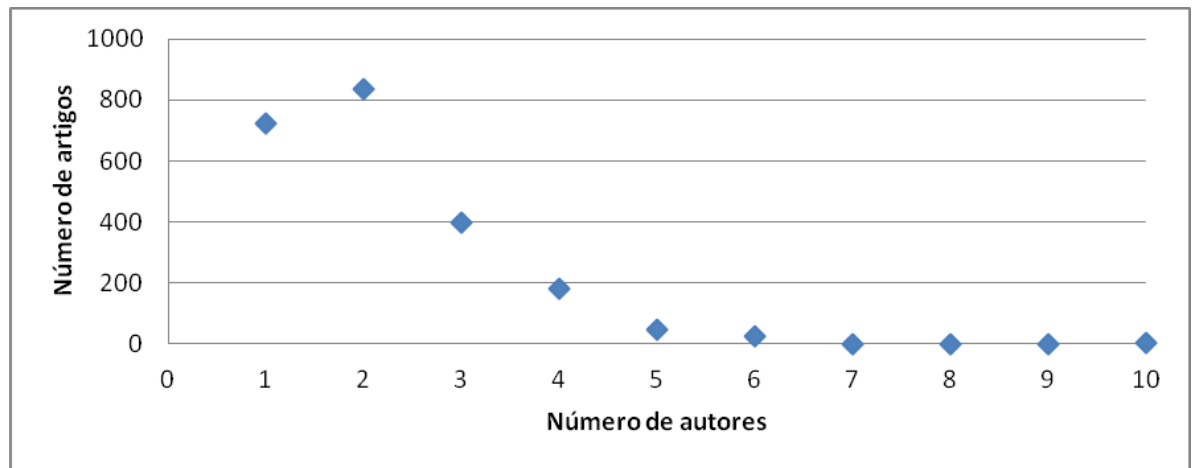

Gráfico 3 Produção Científica em AP no Brasil (2000-2010): número de autores por artigo Fonte: Elaborado pelos autores, a partir dos dados da pesquisa. 
Tabela 3 Produção científica em AP no Brasil (2000-2010): \% de autores/artigo por veículo

\begin{tabular}{l|l|l|l|l|l|l}
\hline $\begin{array}{l}\text { Autores por } \\
\text { artigo }\end{array}$ & EnANPAD & EnAPG & O\&S & RAC & RAP & RSP \\
\hline 1 & $30 \%$ & $25 \%$ & $44 \%$ & $31 \%$ & $34 \%$ & $65 \%$ \\
\hline 2 & $41 \%$ & $37 \%$ & $32 \%$ & $52 \%$ & $39 \%$ & $19 \%$ \\
\hline 3 & $18 \%$ & $21 \%$ & $20 \%$ & $14 \%$ & $16 \%$ & $8 \%$ \\
\hline 4 & $7 \%$ & $12 \%$ & $5 \%$ & $0 \%$ & $6 \%$ & $6 \%$ \\
\hline 5 & $2 \%$ & $3 \%$ & $0 \%$ & $3 \%$ & $2 \%$ & $2 \%$ \\
\hline 6 & $1 \%$ & $1 \%$ & $0 \%$ & $0 \%$ & $2 \%$ & $0 \%$ \\
\hline 7 ou mais & $0 \%$ & $0 \%$ & $0 \%$ & $0 \%$ & $1 \%$ & $0 \%$ \\
\hline
\end{tabular}

Fonte: Elaborado pelos autores, a partir dos dados da pesquisa.

Demonstrado que o campo do saber em AP no Brasil cresceu na última década, tanto no volume da produção científica quanto no tamanho da rede de pesquisadores, e caracteriza-se tendencialmente por publicações de coautoria entre dois autores, é importante a categorização do perfil dos autores.

A tabela 4 expõe que o percentual dos autores considerados como continuantes na comunidade acadêmica de AP no Brasil, ou seja, aqueles que têm uma produção científica ininterrupta, é muito baixo (2,17\%). $\mathrm{O}$ mesmo ocorre com os transientes, autores que não têm a mesma periodicidade de publicação dos continuantes, mas que contribuem com a constância dos projetos de pesquisa no campo do saber (6,55\%). Os one-timers são majoritários na rede de pesquisadores de Administração Pública (71,54\%), ilustrando a atração de pesquisadores de $\mathrm{ADM}$ que publicam esporadicamente alguns artigos nesse campo do saber pelo hibridismo entre Gestão Pública e Gestão Empresarial, bem como os alunos de pós-graduação de AP em nível de mestrado que publicam o resultado da dissertação e não continuam na academia, deslocando-se para o mercado de trabalho. O número de entrantes $(8,61 \%)$ evidencia aqueles que entraram, ultimamente, na rede de pesquisadores, muitos dos quais são alunos de pós-graduação em nível de doutorado ou recém-doutores. Os retirantes são pesquisadores não tão frequentes nas publicações $(11,13 \%)$ e não significa, necessariamente, que abandonaram o campo do saber: aparecem vários professores sêniores de AP que, talvez, já não estejam mais tão empolgados para apresentarem seus artigos em eventos científicos.

Tabela 4 Produção científica em AP no Brasil (2000-2010): categorização do perfil dos autores

\begin{tabular}{l|l|l}
\hline Categoria & $\begin{array}{l}\text { Número de } \\
\text { autores }\end{array}$ & $\begin{array}{l}\text { (\%) da rede de } \\
\text { pesquisadores }\end{array}$ \\
\hline Continuantes & 62 & $2,17 \%$ \\
\hline Transientes & 187 & $6,55 \%$ \\
\hline One-timers & 2044 & $71,54 \%$ \\
\hline Entrantes & 246 & $8,61 \%$ \\
\hline Retirantes & 318 & $11,13 \%$ \\
\hline Total & 2857 & $100 \%$ \\
\hline
\end{tabular}

Fonte: Elaborado pelos autores, a partir dos dados da pesquisa.

O quadro 3 apresenta a lista, em ordem alfabética, dos 62 pesquisadores categorizados como autores continuantes no campo do saber em AP no Brasil na última década, sendo possível verificar a presença de muitos docentes de programas de pós-graduação de $\mathrm{ADM}$ e de AP, professores renomados, bolsistas produtividade em pesquisa, coordenadores e líderes de tema de eventos científicos de AP, bem como alguns alunos de pós-graduação (mestrado e doutorado) na última década. Analisando com precisão as publicações desses 62 pesquisadores continuantes, com o objetivo de averiguar com quem estes publicam, constata-se a coautoria entre eles com pesquisadores one-timers. Nesse caso, infere-se que é uma produção científica baseada, regularmente, na coautoria entre orientadores e orientandos de pós-graduação. 
Quadro 3 Produção Científica em AP no Brasil (2000 a 2010): relação dos pesquisadores continuantes

\begin{tabular}{|c|c|c|}
\hline Ademir Clemente & $\begin{array}{l}\text { Francisco de Assis } \\
\text { Soares }\end{array}$ & $\begin{array}{l}\text { Maria Ceci Araujo } \\
\text { Misoczky }\end{array}$ \\
\hline Alketa Peci & $\begin{array}{l}\text { George Avelino } \\
\text { Filho }\end{array}$ & $\begin{array}{l}\text { Maria Ruth S. D. } \\
\text { Teixeira Leite }\end{array}$ \\
\hline $\begin{array}{l}\text { Allan Claudius } \\
\text { Queiroz Barbosa }\end{array}$ & Gerson Rosenberg & $\begin{array}{l}\text { Monica Cavalcanti } \\
\text { Sa de Abreu }\end{array}$ \\
\hline $\begin{array}{l}\text { Ana Rita Silva } \\
\text { Sacramento }\end{array}$ & $\begin{array}{l}\text { Hans Michael Van } \\
\text { Bellen }\end{array}$ & $\begin{array}{l}\text { Octavio Penna } \\
\text { Pieranti }\end{array}$ \\
\hline $\begin{array}{l}\text { Ana Silvia Rocha } \\
\text { Ipiranga }\end{array}$ & $\begin{array}{l}\text { Ivan Beck } \\
\text { Ckagnazaroff }\end{array}$ & Otavio Prado \\
\hline $\begin{array}{l}\text { Antonio Sergio } \mathrm{A} . \\
\text { Fernandes }\end{array}$ & $\begin{array}{l}\text { Janann Joslin } \\
\text { Medeiros }\end{array}$ & $\begin{array}{l}\text { Paulo Carlos Du Pin } \\
\text { Calmon }\end{array}$ \\
\hline $\begin{array}{l}\text { Armindo dos S. de } \\
\text { S. Teodosio }\end{array}$ & Joao Luiz Passador & $\begin{array}{l}\text { Paulo Eduardo } \\
\text { Moledo Palombo }\end{array}$ \\
\hline $\begin{array}{l}\text { Claudia Souza } \\
\text { Passador }\end{array}$ & \begin{tabular}{|l|} 
Jorge Vianna \\
Monteiro
\end{tabular} & \begin{tabular}{|l|} 
Paulo Roberto \\
Arvate \\
\end{tabular} \\
\hline $\begin{array}{l}\text { Dante Pinheiro } \\
\text { Martinelli }\end{array}$ & \begin{tabular}{|l|} 
Jose Antonio \\
Gomes de Pinho \\
\end{tabular} & $\begin{array}{l}\text { Reginaldo Souza } \\
\text { Santos }\end{array}$ \\
\hline $\begin{array}{l}\text { Deborah Moraes } \\
\text { Zouain }\end{array}$ & $\begin{array}{l}\text { Jose Antonio P. de } \\
\text { Oliveira }\end{array}$ & $\begin{array}{l}\text { Rezilda Rodrigues } \\
\text { Oliveira }\end{array}$ \\
\hline $\begin{array}{l}\text { Denis Alcides } \\
\text { Rezende }\end{array}$ & \begin{tabular}{|l|} 
Jose Carlos \\
Barbieri \\
\end{tabular} & \begin{tabular}{|l|} 
Ricardo Correa \\
Gomes \\
\end{tabular} \\
\hline $\begin{array}{l}\text { Djalma Freire } \\
\text { Borges }\end{array}$ & \begin{tabular}{|l|} 
Jose Roberto \\
Pereira \\
\end{tabular} & $\begin{array}{l}\text { Rogerio Hermida } \\
\text { Quintella } \\
\end{array}$ \\
\hline $\begin{array}{l}\text { Eduardo Cerqueira } \\
\text { Batitucci }\end{array}$ & Klaus Frey & \begin{tabular}{|l|} 
Rosinha da S. \\
Machado Carrion \\
\end{tabular} \\
\hline $\begin{array}{l}\text { Eduardo de Lima } \\
\text { Caldas }\end{array}$ & $\begin{array}{l}\text { Lamounier Erthal } \\
\text { Villela }\end{array}$ & Sandro Cabral \\
\hline $\begin{array}{l}\text { Eliane Salete } \\
\text { Filippim }\end{array}$ & \begin{tabular}{|l|} 
Luciana de $O$. \\
Miranda Gomes \\
\end{tabular} & \begin{tabular}{|l|} 
Sonia Maria Fleury \\
Teixeira \\
\end{tabular} \\
\hline $\begin{array}{l}\text { Elizabeth Matos } \\
\text { Ribeiro }\end{array}$ & $\begin{array}{l}\text { Luciano Antonio P. } \\
\text { Junqueira }\end{array}$ & \begin{tabular}{|l|} 
T. Diana L. V.A. \\
Macedo-Soares \\
\end{tabular} \\
\hline $\begin{array}{l}\text { Elvia Mirian } \\
\text { Cavalcanti Fadul }\end{array}$ & Luis Roque Klering & $\begin{array}{l}\text { Tomas de Aquino } \\
\text { Guimaraes } \\
\end{array}$ \\
\hline $\begin{array}{l}\text { Fernando de Souza } \\
\text { Coelho }\end{array}$ & Marcelo Jose Braga & Valmor Slomski \\
\hline $\begin{array}{l}\text { Fernando } \\
\text { Guilherme Tenorio }\end{array}$ & \begin{tabular}{|l|} 
Marcelo Milano \\
Falcao Vieira \\
\end{tabular} & $\begin{array}{l}\text { Vera Lucia P. Santos } \\
\text { Mendes }\end{array}$ \\
\hline $\begin{array}{l}\text { Fernando Luiz } \\
\text { Abrúcio }\end{array}$ & \begin{tabular}{|l|} 
Marco Aurelio \\
Ruediger \\
\end{tabular} & Vicente Riccio \\
\hline $\begin{array}{l}\text { Flavia de Paula } \\
\text { Duque Brasil }\end{array}$ & $\begin{array}{l}\text { Marcus Vinicius G. } \\
\text { da Cruz }\end{array}$ & - \\
\hline
\end{tabular}

Fonte: Elaborado pelos autores, a partir dos dados da pesquisa.

Em adição, cabe apurar quais são os pesquisadores prolíficos do campo do saber em AP no Brasil na última década. Análises de pesquisadores prolíficos são frequentes em trabalhos sobre a produção científica e rede de pesquisadores, como no estudo de Kellough e Pitts (2005), que investigam os artigos publicados na Public Adminstration Review, um dos principais periódicos de AP do mundo em tradição e no fator de impacto. Dessa forma, considerando o total de publicações em todos os eventos e periódicos analisados, foram selecionados os pesquisadores com, no mínimo, 10 publicações no período de 2000 a 2010 , totalizando 20 autores, dispostos na tabela 5 . O resultado assinala a relação entre os autores continuantes como os pesquisadores mais prolíficos, com exceção dos docentes Marco Aurélio Marques Ferreira e Suely de Fatima Ramos Silveira, que são caracterizados na pesquisa como transientes e pertencem à Universidade Federal de Viçosa (UFV), instituição de ensino que se notabilizou no campo do saber em AP no Brasil a partir de meados da última década, com a implantação de um curso de mestrado acadêmico em ADM com área de concentração em AP no ano de 2005. 
Tabela 5 Produção científica em AP no Brasil (2000-2010): lista dos pesquisadores mais prolíficos

\begin{tabular}{|c|c|c|}
\hline Autor & $\begin{array}{l}\text { Instituição de } \\
\text { Ensino }\end{array}$ & $\begin{array}{l}N^{\circ} \text {. de Publicações } \\
\text { no Periodo }\end{array}$ \\
\hline Alketa Peci & FGV-RJ & 17 \\
\hline Ricardo Correa Gomes & UNB & 17 \\
\hline $\begin{array}{l}\text { Jose Antonio Gomes de } \\
\text { Pinho }\end{array}$ & UFBA & 16 \\
\hline $\begin{array}{l}\text { Marcus Vinicius } \\
\text { Goncalves da Cruz }\end{array}$ & FJP-MG & 16 \\
\hline $\begin{array}{l}\text { Suely de Fatima Ramos } \\
\text { Silveira }\end{array}$ & UFV & 15 \\
\hline $\begin{array}{l}\text { Elvia Mirian Cavalcanti } \\
\text { Fadul }\end{array}$ & $\begin{array}{l}\text { UFBA e } \\
\text { UNIFACS }\end{array}$ & 14 \\
\hline $\begin{array}{l}\text { Maria Ceci Araujo } \\
\text { Misoczky }\end{array}$ & UFRGS & 14 \\
\hline Paulo Roberto Arvate & FGV-SP & 13 \\
\hline Fernando Luiz Abrucio & FGV-SP & 12 \\
\hline Ivan Beck Ckagnazaroff & UFMG & 12 \\
\hline $\begin{array}{l}\text { Marco Aurelio Marques } \\
\text { Ferreira }\end{array}$ & UFV & 12 \\
\hline Marco Aurelio Ruediger & FGV-RJ & 11 \\
\hline $\begin{array}{l}\text { Maria Ruth S. Diniz } \\
\text { Teixeira Leite }\end{array}$ & FJP-MG & 11 \\
\hline $\begin{array}{l}\text { Paulo Carlos Du Pin } \\
\text { Calmon }\end{array}$ & UNB & 11 \\
\hline $\begin{array}{l}\text { Armindo dos S. de } \\
\text { Sousa Teodosio }\end{array}$ & PUC-MG & 10 \\
\hline George Avelino Filho & FGV-SP & 10 \\
\hline Janann Joslin Medeiros & UNB & 10 \\
\hline $\begin{array}{l}\text { Luciana de Oliveira } \\
\text { Miranda Gomes }\end{array}$ & UNB & 10 \\
\hline $\begin{array}{l}\text { T. Diana L. V. A. de } \\
\text { Macedo-Soares }\end{array}$ & PUC-RJ & 10 \\
\hline $\begin{array}{l}\text { Tomas de Aquino } \\
\text { Guimaraes }\end{array}$ & UNB & 10 \\
\hline
\end{tabular}

Fonte: Elaborado pelos autores, a partir dos dados da pesquisa.

Classificando os artigos desses 20 pesquisadores prolíficos do campo do saber em AP brasileiro, conforme os temas de interesse do EnAPG 2012, percebe-se a variedade de objetos de pesquisa que cada um aborda no decorrer da última década. Nessa análise é evidente o distanciamento temático entre as produções científicas desses autores no período de 2000 a 2010, reforçando o pressuposto de Pacheco (2003) de que a agenda de pesquisa em AP é dispersa. Acrescenta-se que, como os autores continuantes são poucos (em torno de $2 \%$ da rede de pesquisadores), é plausível que eles fossem chamados a dar conta de uma miríade de assuntos que perfazem o rol de estudos de AP em nível nacional, favorecendo a amplitude temática de suas publicações em detrimento da especialização (ou verticalização) de suas investigações.

Ainda, vale mencionar que, entre esses 20 autores prolíficos, 12 pertenceram ao comitê científico (ou foram líderes de tema) da área (2000-2008) ou divisão acadêmica de Administração Pública da ANPAD (2009-2017) neste século, bem como alguns são professores sêniores e foram (ou são) editores de periódicos importantes de ADM e AP. Tal fato ilustra a relação crível entre o volume da produção científica do autor e a ocupação de cargos de liderança nas associações de pesquisa e congressos acadêmicos. Em relação às instituições de ensino (IES), 80\% dos professores pertencem a IES que têm tradição de longa data no ensino e/ou pesquisa em Administração Pública no Brasil, como FGV-RJ, FGV-SP, UFBA, UFRGS, UFMG, UNB e FJP-MG. Atualmente, pelo cadastro do CNPq (ano base de 2018), um terço desses 20 professores tem bolsa de produtividade em pesquisa na área de Administração. 


\subsection{Ilustração da Rede de Pesquisadores e as Medidas de Propriedade Estrutural}

A rede de pesquisadores de Administração Pública no Brasil, na última década, formada a partir dos autores dos 2.218 artigos que compuseram a amostra desta investigação, ilustra a sua estrutura. A figura 2 demonstra que o número de pontos isolados (autores únicos de um ou mais artigos), em comparação com a quantidade de pontos conectados (coautoria de um ou mais artigos), é visivelmente inferior, isto é, a colaboração entre os autores é evidente.

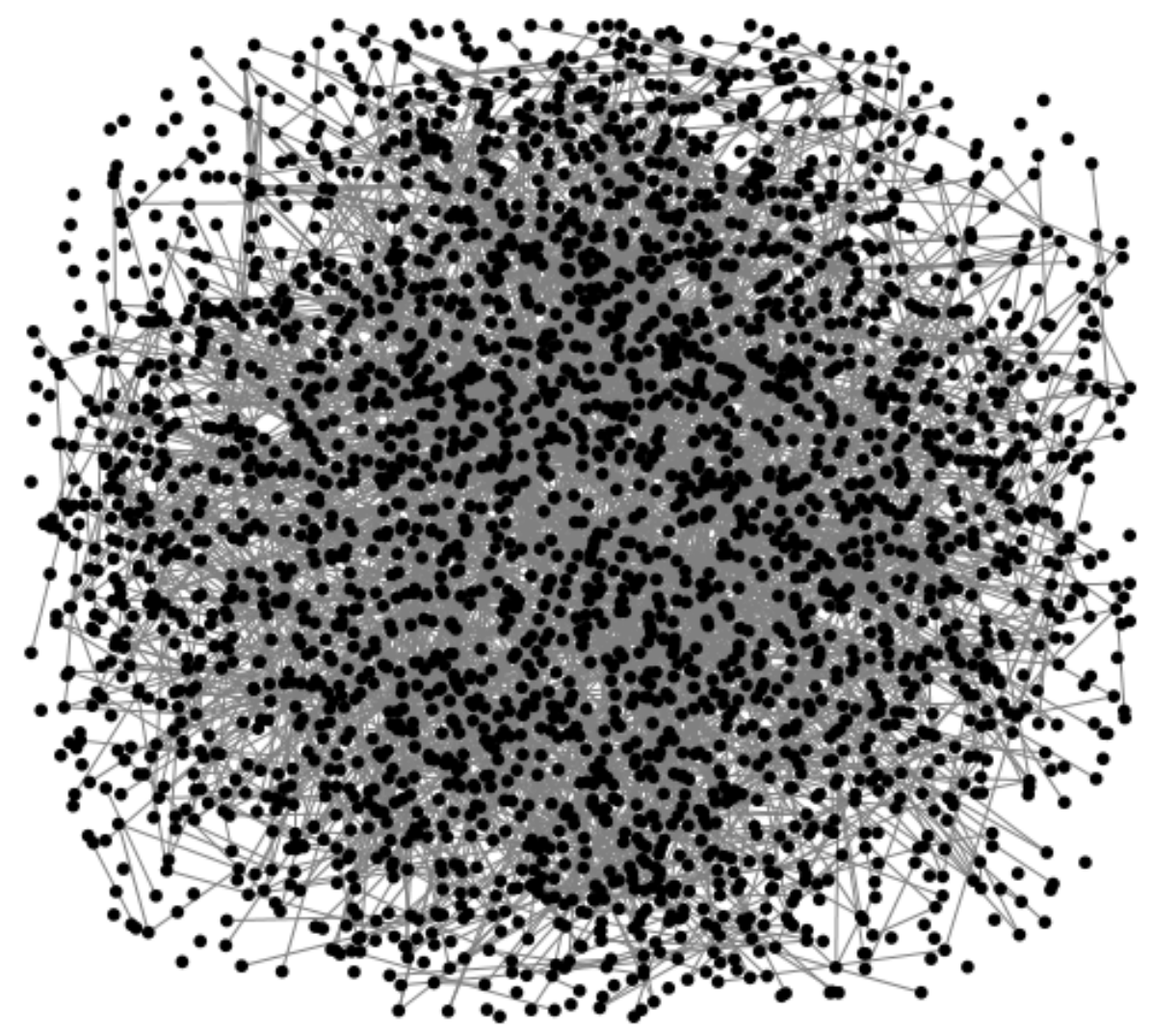

Figura 2 Produção científica em AP no Brasil (2000-2010): grafo da rede de pesquisadores Fonte: Elaborado pelos autores, a partir dos dados da pesquisa.

Concernente às medidas de propriedade estrutural da rede de pesquisadores, quer dizer, a centralidade de grau (degree), a centralidade de intermediação (betweenness) e a medida de autovetor (eigenvector), a tabela 6 apresenta os resultados. A centralidade de grau dos pesquisadores da rede de AP, na última década, revela os autores que se destacaram no nível de colaboração. Nesse caso, encontraram-se quatro docentes, entre os 2.857 autores, com diversas conexões que os tornam centrais em tal rede. Todos são igualmente prolíficos, denotando que a produção científica que realizam é, além de colaborativa, expressiva na quantidade de artigos publicados. Enfim, como são professores sêniores, que lideram eventos e/ou editam revistas científicas, é verossímil que tenham inúmeras possibilidades de se associar a diversos coautores, ocupando, assim, uma posição central na rede de pesquisadores.

A centralidade de intermediação, por sua vez, mostra o quanto um pesquisador pode interligar autores que não estão diretamente conectados. A intermediação se dá pela localização do autor na rede de pesquisadores oportunizada, por exemplo, pela coordenação de programa de pós-graduação, pela função de organização de eventos, pelo trânsito entre campos do saber diferentes e pela liderança de projetos temáticos em agências de fomento. Destaque, nesse caso, para a professora Alketa Peci (FGV-RJ), que além de prolífica e com 
centralidade de grau, possui um valor considerável de intermediação, confirmando sua proeminência na rede de pesquisadores de AP no período de 2000 a 2010.

Finalizando, a medida de autovetor destaca a relação, na rede de pesquisa, entre os pesquisadores que apresentam alto valor de associações/conexões, destacando-se as parcerias entre autores colaborativos que trabalham, muitas vezes, no mesmo grupo de pesquisa. Nesse caso, o realce na última década foi para os professores da UFV, Suely de Fátima Ramos Silveira e Marco Aurélio Marques Ferreira.

Tabela 6 Produção científica em AP no Brasil (2000-2010): medidas de propriedade estrutural

\begin{tabular}{|c|c|c|}
\hline \multicolumn{2}{|c|}{ Centralidade de Grau } \\
\hline Pesquisador & Degree & Medida Normalizada \\
\hline Suely de Fátima Ramos Silveira & 26 & 0,00916 \\
\hline Marco Aurélio Marques Ferreira & 19 & 0,00669 \\
\hline Ricardo Correa Gomes & 18 & 0,00634 \\
\hline Alketa Peci Centralidade de Intermediação & 0,00599 \\
\hline Pesquisador & 17 & 0,009 \\
\hline Alketa Peci & Betweeneess Centrality \\
\hline Ricardo Luiz Pereira Bueno & 0,008 \\
\hline Putovetor & Eigenvector \\
\hline Suely de Fátima Ramos Silveira & 0,00023 \\
\hline Marco Aurélio Marques Ferreira & 0,00017 \\
\hline
\end{tabular}

Fonte: Elaborado pelos autores, a partir dos dados da pesquisa.

\section{Considerações Finais}

À guisa de conclusão, pode-se afirmar que o artigo tanto reforça alguns resultados de pesquisas anteriores, confirmando quantitativamente por índices bibliométricos e de análise de rede algumas apreciações qualitativas, como aporta alguns achados sobre a produção científica em Administração Pública no Brasil na última década. Os argumentos de falta de identidade e insuficiente delimitação do campo do saber em AP, de dispersão e "vale tudo" temático, foram ratificados. E, de maneira inédita, demonstrou-se que a comunidade acadêmica de AP foi circunscrita a 62 autores continuantes entre 2000 e 2010, embora o volume da produção científica e o tamanho da rede de pesquisadores cresceram incontestavelmente nesse período.

Em linhas gerais, o crescimento do volume de publicações (total de 2.218 artigos) e do número de pesquisadores (montante de 2.857 autores diferentes), sobretudo a partir de meados dos anos 2000, com picos bienais, relaciona-se com o surgimento do EnAPG, o evento da Divisão de Administração Pública da ANPAD. Entretanto, ressalta-se que o aumento dessa produção científica não corresponde ao aumento das publicações de professores e alunos oriundos de programas de pós-graduação em AP (ou com área de concentração ou linha de pesquisa nesse campo do saber), mas pela visita de pesquisadores de ADM das diversas áreas funcionais, categorizados como autores one-timers, que escrevem, geralmente, sobre Administração Pública como locus (objeto empírico) e não de AP como focus (referencial teórico). Essa visitação no campo do saber em AP na última década é explicada pelo movimento da Reforma Gerencial 
e pelo paradigma sociocêntrico que interpenetra Estado, mercado e terceiro setor na prestação de serviços públicos e na provisão de políticas públicas[vi]. O entendimento do que é público extrapolou nitidamente a noção do espaço governamental na agenda de pesquisa, ampliando as temáticas de investigação e atraindo pesquisadores de múltiplas subáreas da Administração de Empresas.

Ademais, a categorização de $71,5 \%$ da rede de pesquisadores de AP como autores one-timers, que publicaram um artigo no período 2000-2010, e de 2,2\% como autores continuantes, com produção científica constante no período, revela que, a despeito da explosão quantitativa de publicações, a comunidade acadêmica carece de amadurecimento das linhas de pesquisa e de fidelização dos pesquisadores, o que depende, invariavelmente, do incentivo aos programas de pós-graduação de Administração Pública e de Administração (de Empresas) com professores, disciplinas e grupos de pesquisa em AP.

Em relação aos 20 pesquisadores prolíficos de AP identificados na última década, constatou-se, naturalmente, que 18 são autores continuantes e 16 possuem vínculo como professores de instituições de ensino superior que têm, historicamente, programas (ou linhas de pesquisa) de pós-graduação de Administração Pública. $\mathrm{Na}$ verificação da produção científica desses pesquisadores, muitos dos quais professores sêniores, bolsistas produtividade do CNPq, líderes de eventos e congressos no campo do saber em AP, observou-se que eles tratam de temas variados nos artigos; ou seja, o período entre os anos 2000 e 2010 foi marcado pela amplitude temática de suas publicações em detrimento da especialização, algo que pode ser interpretado não pelas publicações que os pesquisadores realizam com seus orientandos de pós-graduação, mas pelo fato de serem os experts da área e serem impelidos a abordarem os vários temas em voga que figuram na pauta governamental.

Para além do crescimento do campo do saber em AP na última década, notou-se um padrão colaborativo nas publicações com frequência modal de coautoria entre dois pesquisadores. Dentre os dois eventos e os quatro periódicos que compuseram a amostra desta investigação, apenas a Revista do Serviço Público apresentou um índice de colaboração no qual dois terços dos artigos eram de autoria de um pesquisador, o que é explicado pelo viés profissional da publicação e pelo perfil de practtioners dos autores, geralmente gestores públicos que são mestres ou doutores, que não enfatizam a tradição acadêmica de coautoria.

Entretanto, o crescimento da produção científica de AP nos eventos não foi acompanhado proporcionalmente pelos periódicos, cabendo, como agenda de pesquisa no futuro, investigar: (i) se a produção científica dos eventos é submetida para revistas que não foram analisadas neste trabalho; (ii) se o não crescimento do volume da produção científica de AP nos periódicos tradicionais analisados nesta investigação deve-se à baixa qualidade dos artigos (em todas as revistas) e/ou à secundarização da AP na linha editorial da O\&S e RAC; e (iii) se havia (e se persiste nesta década) uma carência de revistas de Administração Pública ou de ADM que abarquem o eixo temático de AP para absorver a produção científica. Não obstante, é válido assinalar que, no período de 2000 a 2010, as pressões por publicações em periódicos não eram tão acentuadas como são nos anos correntes. Grosso modo, o incentivo pró-revista ficou mais patente no final da última década.

Em adição, o projeto de pesquisa do qual deriva este artigo permitiu, sob a ótica de redes complexas, ilustrar, visual e estaticamente, a rede de pesquisadores em AP no país, calculando suas medidas de propriedade estrutural. A partir dos 2.857 autores que formaram tal rede na última década, considerando os principais eventos e periódicos que compuseram a amostra desta investigação, a centralidade de grau e de intermediação destacou, simultaneamente, a pesquisadora Alketa Peci, da FGV-RJ, ex-coordenadora da Divisão Acadêmica de Administração Pública da ANPAD no triênio 2015-2017 e editora da Revista de Administração Pública (RAP).

Uma das limitações deste trabalho foi a não abordagem da Administração Pública em sentido lato sensu, ou seja, a consideração do campo do saber para além da comunidade acadêmica de AP na área de Administração, não incluindo os eventos como o Encontro de Gestão Social (EnAPEGS) e o Encontro da Associação Nacional de Pós-Graduação e Pesquisa em Ciências Sociais (ANPOCS) no grupo de trabalho de Políticas 
Públicas, bem como alguns periódicos tradicionais, como a Revista de Administração de Empresas (RAE) e a Revista da Administração da Universidade de São Paulo (RAUSP); conquanto, uma análise prévia dessas revistas demonstrou que os artigos que tratassem de AP eram raros.

Sobre implicações gerenciais deste artigo para a gestão universitária e do Sistema de C\&T no Brasil, podese afirmar que a persistência da falta de identidade e insuficiente delimitação do campo do saber em AP no país fragilizam tal formação acadêmica na pós-graduação nacional. No âmbito do ensino de graduação, a distinção de Diretrizes Curriculares Nacionais entre Administração e Administração Pública pelo MEC, a partir de 2014, contribuem para a emergência do Campo de Administração e Gestão, Políticas Públicas no país $^{\text {[vii] }}$. Entretanto, na área de avaliação de ADM na pós-graduação na CAPES, mesmo com a inclusão do nome Administração Pública na nomenclatura em 2016 (Administração Pública e de Empresas, Ciências Contábeis e Turismo), a diferenciação entre Administração de Empresas (AE) e Administração Pública (AP) permanece tênue e impõe a criação de uma subárea. O hibridismo entre AE e AP, sobretudo na definição do QUALIS, sem considerar a especificidade da produção científica de AP, prejudica a avaliação dos programas de pós-graduação desse campo do saber.

Finalizando, sobre a agenda de pesquisa oriunda deste artigo, sugere-se uma investigação, a partir de 2021, que realize um balanço do período de 2011 a 2020. Existem indícios, baseados no surgimento de muitos eventos (Encontro Brasileiro de Administração Pública - EBAP - e Encontro Nacional de Ensino e Pesquisa do Campo de Públicas - ENEPCP -, por exemplo), de diversos periódicos no campo de saber (Cadernos Gestão Pública e Cidadania, da Fundação Getúlio Vargas - FGV -, e Administração Pública e Gestão Social, da Universidade Federal de Viçosa - UFV) e de novos programas de pós-graduação com ênfase em de AP no decorrer desta década, de um incremento expressivo do volume da produção científica e do tamanho da rede de pesquisadores. Resta saber, no entanto, se as problemáticas de longa data do campo do saber de AP no Brasil, que perduraram em certa medida nos anos 2000, continuam perseverando nos últimos anos.

\section{REFERÊNCIAS}

Andion, C. (2012). Por uma Nova Interpretação das Mudanças de Paradigma na Administração Pública. Cadernos EBAPE.BR, 10(1), 1-19.

Bhen, R. D. (1995). The Big Questions of Public Management. Public Administration Review, 55(4), 313-324.

Bourdieu, P. (2004). Usos sociais da ciência. Livraria UNESP.

Fadul, E. M. C., \& Silva, M. A. M. (2009) Limites e possibilidades disciplinares da administração pública e dos estudos organizacionais. Revista de Administração Contemporânea, 13 (3), 351-365.

Fadul, E., \&; Silva, M. A. M., \& Silva, L. P. (2010, setembro) Ensaiando Explicações e Explorando Caminhos para o Campo da Administração Pública. Anais do Encontro da Associação Nacional de Programas de Pós-graduação em Administração, Rio de Janeiro, RJ, Brasil, 34.

Fadul, E., \& Silva, L. P., \& Cerqueira, L. S. (2011) Uma Análise do Campo da Administração Pública através da Produção Científica Publicada nos Anais dos EnAPGs. Cadernos Gestão Pública e Cidadania, 16(59), 1-16.

Fadul, E., \& Coelho, F. S., \& Costa, F. J. L., \& Gomes, R. C. (2012, setembro). Apontamentos sobre o Campo do Saber de Administração Pública no Brasil: uma reflexão a partir da Divisão Acadêmica de Administração Pública da ANPAD (2009 - 2012). Anais do Encontro da Associação Nacional de Programas de Pós-graduação em Administração, Rio de Janeiro, RJ, Brasil, 36.

Fadul, E., \& Coelho, F. S., \& Costa, F. J. L., \& Gomes, R. C. (2014). Administração pública no Brasil: reflexões sobre o campo de saber a partir da Divisão Acadêmica da Associação Nacional de Pós-Graduação e Pesquisa em Administração (2009-2013). Revista Brasileira de Administração Pública - RAP, 48(5), 1329-1354.

Graeml, A.R., \& Macadar, M.A., \& Guarido Filho, E.R., \& Rossoni, L. (2010) Redes Sociais e Intelectuais em Administração da Informação: uma análise cientométrica do período 1997-2006. Informação e Sociedade, 20, 95-110. 
Henry, N. (1975). Paradigms of public administration. Public Administration Review, 35 (4), 378-386.

Hocayen-da-Silva, A.J., \& Rossoni, L., \& Ferreira Junior, I. (2008). Administração pública e gestão social: a produção científica brasileira entre 2000 e 2005. Revista de Administração Pública - RAP, 42(4), 655-680.

Keinert, T. M. M. (2000). Administração Pública no Brasil: crises e mudanças de paradigmas. Annablume.

. (2014). O Movimento "Campo de Públicas": construindo uma comunidade científica dedicada ao interesse público. Revista Administração Pública e Gestão Social - APGS, 6(4), 168-219.

Keinert, T. M. M. (1994). Os paradigmas da administração pública no Brasil (1900-92). Revista de Administração de Empresas - RAE, 34(3), 41-48.

Kellough, E.J., \& Pitts, D.W. (2005). Who contributes for Public Administration Review? Examining the characteristics of author who submit manuscripts to the journal. Public Administration Review, 65(1), 3-7.

Machado-da-Silva, C., \& Amboni, N., \& Cunha, V. C. (1990, setembro) Organizações: o estado da arte da produção acadêmica do Brasil. Anais do Encontro da Associação Nacional de Programas de Pós-graduação em Administração, Belo Horizonte, MG, Brasil, 15.

Martins, G. S. (2009). A Construção do Conhecimento Científico no Campo de Gestão de Operações no Brasil: uma análise sob a ótica de Redes Sociais do período 1997-2008 (Dissertação de mestrado). Fundação Getúlio Vargas - FGV, São Paulo, SP, Brasil.

Martins, G. S., \& Rossoni, L., \& SCILLAG, J. M., \& Martins, M. E., \& Pereira, S. C. F. (2010). Gestão de Operações no Brasil: Uma análise do Campo Científico a partir da Rede Social de Pesquisadores. Revista de Administração de Empresas - RAE, 9 (2), 1-26.

Ospina Bozzi, S. M. (1998). La administración pública como comunidad discursiva: algunas lecciones del caso estadounidense para América Latina. Reforma y Democracia, 10, 85-112.

Pacheco, R. S. (2003). Administração Pública nas Revistas Especializadas - Brasil, 1995-2002. Revista de Administração de Empresas - RAE, 43 (4), 63-71.

Peci, A., \& Ribeiro, A.J.G., \& Rodrigues, F.B.S., \& Forzanin, M. (2011, setembro). Paradigmas Orientadores da Pesquisa em Administração Pública no Contexto Brasileiro. Anais do Encontro da Associação Nacional de Programas de Pós-graduação em Administração, Rio de Janeiro, RJ, Brasil, 35.

Pires, V., \& Silva, S. M., \& Fonseca, S. A., \& Vendramini, P., \& Coelho, F. S. (2014). Dossiê - Campo de Públicas no Brasil: definição, movimento constitutivo e desafios atuais. Revista Administração Públiva e Gestão Social APGS, 6(3), 109-167.

Rossoni, L., \& Ferreira Junior, I., \& Hocayen-da-Silva, A.J.. (2009). Administração de Ciência e Tecnologia: A Produção Científica Brasileira entre 2000 e 2005. Revista de Administração da Unimep, 7 (3), 1-23.

Rossoni, L., \& Guarido Filho, E.R., \& Machado-da-Silva, C. (2010). A questão da agência em redes acadêmicas de pesquisa: colaboração, preferência e continuidade. Revista Hispanica para el Análisis de Redes Sociales, 19 (5), $87-113$.

Rossoni, L., \& Hocayen-da-Silva, A.J. (2008). Cooperação entre Pesquisadores da Área de Administração da Informação: Evidências Estruturais de Fragmentação das Relações no Campo Científico. Revista de Administração - RAUSP, 43 (2), 138-151.

Smolscki, F. M.; \& Dalcin, D.; \& Visentini, M.; \& Bamberg, J.; \& kern, J. S. (2017). Análise do perfil da produção científica da Revista de Administração Pública (RAP) no período 2003-16. Revista de Administração Pública RAP, 51 (5), 1139-1163.

Souza, C. (1998). Pesquisa em Administração Pública no Brasil: uma agenda para debate. Revista de Administração Pública, 32 (4), 43-61.

\section{Notas}

I Sistemas Complexos (SC) se encaixam no projeto de pesquisa deste artigo por permitirem uma visualização e uma compreensão de comunidades acadêmicas e de suas produções científicas a partir da análise de redes complexas. 
II Esta seção sistematiza, sobretudo, os argumentos dos trabalhos/autores apresentados na tabela 1, na introdução do artigo.

III Muitas vezes, a AP é tratada com uma área funcional da ADM e não como um campo do saber que, no Brasil, antecede a área de management no ensino superior (oferta do curso de graduação em Administração Pública da FGV-SP, a partir de 1952) e na publicação científica (edição da Revista do Serviço Público, desde 1937). Um exemplo é a inclusão apenas recentemente do nome Administração Pública na nomenclatura da área de avaliação de Administração, Ciências Contábeis e Turismo da CAPES, resultado de uma articulação da Sociedade Brasileira de Administração Pública (SBAP) com a coordenação de tal área no quadriênio 2013-2016.

IV A RAP, embora seja um periódico voltado para a área de Administração Pública, no período analisado publicou muitos artigos em diversos números que não versavam sobre Administração Pública, Gestão Pública ou políticas públicas, o que pode ser explicado, hipoteticamente, pelo hibridismo da formação acadêmica dos editores e pela reorientação da EBAP/ FGV para EBAPE (com E de empresarial) a partir de 2002, bem como pela provável submissão de artigos de AP em número e/ou qualidade aquém do fluxo de avaliação e da periodicidade da revista.

V Tema 1: Estado, Sociedade, Governo e Administração Pública; Tema 2: Políticas Públicas; Tema 3: Federalismo, Relações Intergovernamentais e Descentralização; Tema 4: Planejamento, Finanças e Controle no Setor Público; Tema 5: Dimensões Intraorganizacionais das Organizações Públicas; Tema 6: Organização e Gestão de Serviços Públicos; Tema 7: Teorias e Metodologias em Administração Pública; Tema 8: História, Memória e Construção de Agendas de Pesquisa.

VI Sobre os paradigmas da Administração Pública brasileira no século XX, ver o trabalho de Keinert (2000). Para uma reinterpretação na a última década - anos 2000 - , ver o trabalho de Andion (2012).

VII Sobre o movimento Campo de Públicas no ensino de graduação em Administração Pública, Gestão Pública e políticas públicas no Brasil, ver: Pires et al (2014) e Keinert (2014).

\section{BY-NC-ND}

